\title{
CRENAS
}

CENTRO RICERCHE

ECONOMICHE NORD SUD

Università di Cagliari

Università di Sassari

Trust Responsiveness:

On the Dynamics of Fiduciary Interactions

Vittorio Pelligra

\section{WORKING PAPERS}

\author{
$2006 / 15$
}




\section{CENTRO RICERCHE ECONOMICHE NORD SUD \\ ( C R E N O S ) \\ U N IVERS I T À D I CAGLIARI \\ U N IVERSITÀ DI SASS ARI}

Il CRENoS è un centro di ricerca istituito nel 1993 che fa capo alle Università di Cagliari e Sassari ed è attualmente diretto da Raffaele Paci. Il CRENoS si propone di contribuire a migliorare le conoscenze sul divario economico tra aree integrate e di fornire utili indicazioni di intervento. Particolare attenzione è dedicata al ruolo svolto dalle istituzioni, dal progresso tecnologico e dalla diffusione dell'innovazione nel processo di convergenza o divergenza tra aree economiche. Il CRENoS si propone inoltre di studiare la compatibilità fra tali processi e la salvaguardia delle risorse ambientali, siaglobali sia locali.

Per svolgere la sua attività di ricerca, il CRENoS collabora con centri di ricerca e università nazionali ed internazionali; è attivo nell'organizzare conferenze ad alto contenuto scientifico, seminari e altre attività di natura formativa; tiene aggiornate una serie di banche dati e ha una sua collana di pubblicazioni.

www.crenos.it

info@crenos.it

CRENOS - CAGLIARI VIA SAN GIORGIO 12, I-09100 CAGLIARI, ITALIA TEL. + 39-070-6756406; FAX +39-070-6756402

CRENOS - SASSARI

VIA TORRE TONDA 34, I-07100 SASSARI, ITALIA TEL. + 39-079-2017301; FAX + 39-079-2017312

Titolo: Trust Responsiveness: On the Dynamics of Fiduciary Interactions

IS BN $88-8467-358-5$

Prima Edizione Dicembre 2006

(C) 2002 CUEC 2004

Via Is Mirrionis, 1

09123 Cagliari

Tel./Fax 070291201

ww w. cuec.it 


\title{
Trust Responsiveness: \\ On the Dynamics of Fiduciary Interactions
}

\author{
Vittorio Pelligra \\ Department of Economics and Crenos \\ University of Cagliari \\ v.le S.Ignazio 17 \\ 09123 Cagliari - Italy \\ pelligra@unica.it
}

\begin{abstract}
:
Trust and trustworthiness are key elements, both at the micro and macro level, in sustaining the working of modern economies and their institutions. However, despite its centrality, trust continues to be considered as a "conceptual bumblebee", it works in practice but not in theory. In particular, its behavioural rationale still represents a puzzle for traditional rational choice theory and game theory. In this paper "trust responsiveness", an alternative explanatory principle that can account for trustful and trustworthy behaviour, is proposed. Such principle assumes that people can be motivated to behave trustworthily by trustful actions. The paper discusses the philosophical roots, the historical development, as well as the relational nature of this principle as well as its theoretical implications.
\end{abstract}

Keywords: Trust, Trustworthiness, Game Theory, Adam Smith JEL classification numbers: Z13, B31, C7.

Aknowledgement: I owe very much to Michael Bacharach, (†), Luigino Bruni, Benedetto Gui, Shaun Hargreaves-Heap, Mozaffar Qizilbash, Chris Starmer, Robert Sugden and Stefano Zamagni with whom I had the privilege to discuss many of the ideas expressed in this paper. The usual disclaimer applies. 


\title{
Trust Responsiveness: \\ On the Dynamics of Fiduciary Interactions
}

\author{
That reason, passion, answer one great aim; \\ That true self-love and social are the same; \\ That virtue only makes our bliss below; \\ And all our knowledge is, ourselves to know.
}

Alexander Pope, Essay on Man IV

\section{Introduction}

According to John Locke, trust and trustworthiness constitute the vinculum societatis, the bond of society $(1660 / 1954)$, namely, the quality of interpersonal relationships which makes people's agreements work. Without trust our societies would collapse into a Hobbesian "state of nature". More recently, it has also been argued that even the market order needs a certain amount of trust diffused among the agents as a precondition for its efficient functioning (Bruni \& Sugden, 2000). Thus, trust and trustworthiness are perceived as being key elements, both at the micro and macro level, in sustaining the working of modern societies and their institutions. However, despite its centrality, trust continues to be considered as a "conceptual bumblebee", it works in practice but not in theory. In particular, its behavioural rationale still represents a puzzle for traditional game theory, the theory of strategic interactions. This unsatisfactory state of affairs has recently stimulated the development of several alternative models of strategic behaviour that incorporate altruist (Margolis, 1982), inequity averse (Fehr \& Schmidt, 1999), team-thinking (Sugden, 1993) and reciprocal (Rabin, 1993) agents, proposed to disentangle the theoretical and empirical puzzle of pro-social behaviour.

In this paper "trust responsiveness", an alternative explanatory principle that can account for trustful and trustworthy behaviour, is proposed and discussed. Such a principle assumes that people can be 
motivated by trustful actions to behave trustworthily. The relational nature of this principle and its implications are discussed.

While most of the other behavioural principles among those quoted above have been the focus of a huge literature and have benefited from extensive analysis, the idea of trust responsiveness is relatively new. Such a novelty reflects on a lack of philosophical foundations and context. The trust responsiveness hypothesis has received considerable empirical support from a number of experimental studies (Bacharach et al., 2004; Dufwenberg \& Gneezy, 2000; Pelligra, 2002, 2005), yet they all remain silent about its more general rationale. In this paper I will try to fill this gap by creating a context and by introducing some foundational elements that may philosophically establish the concept. The relational nature of the concept will be explored and used to differentiate trust responsiveness from any alternative explanations.

\section{Trust and its elements.}

To isolate the basic elements involved in a trusting interaction we may use the Trust Game depicted in figure 1. Such an interaction summarises the most important elements involved in a trusting situation:

i) potential positive consequences for the trustor: described by $c>a$

ii) potential negative consequences for the trustor: described by $b<a$;

iii) temptation for the trustee or risk of opportunism for the trustor: formalised by $e>f$; 
Figure 1. "The Trust Game"

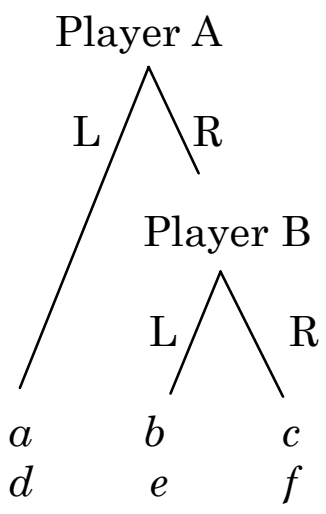

$b<a<c ; f<e ;$

In this game Player A (trustor) can first choose either L or R; in choosing $\mathrm{L}$ players get a payoffs pair equal to $(a, d)$. But if $\mathrm{A}$ chooses $\mathrm{R}$, the choice passes to B (trustee), who, in turn, can choose either L or R. In the first case $\mathrm{B}$ gets $e$ and $\mathrm{A}, b$; in the second case $\mathrm{B}$ gets $f$ and $\mathrm{A}$ gets $c$. When A plays R she is said to be trustful; when B plays R he is said to be trustworthy or, when he plays L, opportunistic. What is worth noticing is that a rational choice account of agents' behaviour in such a situation suggests that $\mathrm{B}$ would play $\mathrm{L}$ and that consequently, by backward induction, A would play $\mathrm{L}$ as well. ${ }^{1}$ This strategy pair determines an equilibrium outcome that is inefficient compared to the one that could be obtained from a couple of trustful and trustworthy choices.

Thus, within the framework of game theory, trustful and trustworthy behaviours cannot be explained as patently irrational. This results casts serious doubts about the usefulness of such a narrow concept of strategic rationality. As stressed by Martin Hollis, in fact, "Reason should be able to show us what makes for a reliable social order, where people find it rational to trust one another. Yet, at least in some

1 The strategy pair (L,L) is a subgame perfecr Nash equilibrium of the "Trust Game". 
current versions, it apparently bids us to play the games of social life in ways which make losers of us all. This applies especially to the suggestions that trust is a matter of mutual self-interest" (1998, p.44). Where should we look for inspiration? How to supplement game theoretic models in order to make them capable of incorporating such a crucial social element?

Responsive trust is the particular conception of trust I aim to discuss here. This variant considers trust as a "relational" concept that can only be defined by focussing on the interaction between subjects' (trustor and trustee) intentions and actions and not merely by referring to the consequences of their actions. The main feature of trust, in this particular meaning, refers to the fact that an explicit act of trust has the peculiarity of "inducing" or "eliciting", to some degree, a trustworthy response. In this respect, trust is said to be responsive or self-fulfilling. This particular conception highlights some important aspects that other conceptions of trust tend to disregard as, for instance, its relational nature - that will be diffusely discussed below-. An act of trust implies a relation between two subjects. Altruism, inequity-aversion and teamthinking models depict subjects that are "closed" to mutual influences. Their actions and beliefs are not affected in any way by a single act of trust. One's trustfulness and trustworthiness are exogenously given in all the three "non-responsive" conceptions. More specifically, all the potential reasons why one should be trustworthy are independent of the act of trust and are considered exogenous. Contrastingly, the responsive version assumes that at least some of the reasons underlying trustworthiness are endogenously produced within the relation by the act of trust itself.

\section{Trust responsiveness.}

Suppose we have two agents, $\mathrm{A}$ and $\mathrm{B}^{2}$. According to the "trust responsiveness hypothesis", B's trustworthiness may be induced by A when she manifestly and consciously chooses a trustful course of action. This kind of inducement assumes the existence of a psychological mechanism according to which A's trustful action motivates B to reward such a trustfulness, making him behave trustworthily, even though such behaviour implies some material cost.

2 I will be using "she" for A and "he" for B. 
As far as I know, the first mention of a similar process, defined as "therapeutic trust", can be found in Horsburgh's 1960 paper. According to this view, in a situation similar to that described in the Trust Game, "One of the reason for (A's) willingness to risk the loss of his money is a belief that this may induce (B) to act more honourably than he originally intended". Following Horsburgh, "therapeutic trust" is defined as a "reliance which aims at increasing the trustworthiness of the person in whom it is placed" (1960, p.346). A peculiar aspect of "therapeutic trust" is that it requires the person trusted to be aware of the reasons for the trust which is placed in him and that the trustful action explicitly aims at increasing the trustee's trustworthiness. One episode of Victor Hugo's Les Miserables exemplifies well such an extreme form of trust. In his book Hugo tells the story of the human resurrection of Jean Valjean who, after having been kept in prison for nineteen years (five years for house-breaking and burglary; fourteen years for having attempted to escape on several occasions) struggles for the rest of his life to become an honest men. The turning point of his story from evil to good is the protagonist's encounter with Bishop Myriel. One night, having been released from prison, Jean Valjean was wandering looking for a place to spend the night. Having been thrown out from all the inns, he knocked at the bishop's door. Without revealing his identity, the bishop gave him an unexpectedly warm welcome, a dinner and a clean bed to sleep. As a response, Valjean disappears during that night Jean with the house silverware.

The day after, having been caught by the police, Jean Valjean is taken back to the bishop's house for inquiries. When the bishop sees him he does not accuse him, on the contrary, he guarantees for him and lets him go with the loot. Just before he is released, the bishop approaches him and says in his ear: "Do not forget, never forget (...) Jean Valjean, my brother, you no longer belong to evil, but to good. It is your soul that I buy from you; I withdraw it from black thoughts and the spirit of perdition, and I give it to God". The action of letting him go can be seen as an extreme form of therapeutic trust, as conceived by Horsburgh, that, in that case, successfully triggers Jean Valjean's resolute will of redemption.

Other forms of "responsive trust", less extreme or purposive, have been described especially in the philosophical literature. Recently Philip Petitt (1995) has suggested a particular use of the term trust (trustfulness in our terminology) as interactive reliance. We observe an 
instance of interactive reliance when, while relying on B, A thinks that her manifest reliance will strengthen B's existing reasons to do that which A relies on him to do. That is so because A believes that, once her reliance is manifested, the utility B gets from fulfilling A's expectations increases with the recognition that doing so will serve A's purposes. The reasons why the trustee's utility would increase by behaving trustworthily in that given situation may have to do, according to Pettit, both with endogenous traits displayed by the trustee and with an endogenous process of belief formation. Consider such first traits as loyalty, virtue and prudence. If $\mathrm{A}$ knows that $\mathrm{B}$ is a loyal individual, she has ground for trusting him; for B fulfilling that trust would mean being reinforced in his reputation for being loyal. Suppose now B has a desire for a virtuous life. A's act of trust gives him the opportunity (by showing trustworthiness) of conforming to that ideal of virtuous life, thus fulfilling his appetite for virtuousness. The third reason why the trustee's utility would increase by being trustworthy is related, according to Pettit, to considerations of prudence. If $\mathrm{B}$ is interested in starting and supporting a long-term relationship, then he may be motivated to refrain from opportunism. Trustworthiness would assure him of a longstanding relationship with $\mathrm{A}$ and consequently with all the opportunities for increasing his utility that may derive from it. However, this kind of explanation is not particularly original, as it refers to a mix of encapsulated and long-run self-interest. The second part of Pettit's explanation, however, is more interesting for my purposes, as it refers to the existence of an original desire for the good opinion of the others. Such a desire, according to Pettit, represents a shameful disposition, not a trait that many will be proud to acknowledge. The existence of this desire implies that by manifesting her reliance, $\mathrm{A}$ is implicitly signalling her belief about B's trustworthiness. For B that belief constitutes a valuable good that, however, can only be enjoyed by actually behaving trustworthily.

Other scholars have stressed this point. According to Jonathan Baron, for instance, "Following the norm of trust has an effect on both the beliefs and the norms of others. It creates a virtuous circle (...) if we act as if we expect the best from the others, they will often behave better as a result" (Baron, 1998, p. 411). A similar process has been the focus of many psychological studies. In his review of this strand of literature, Lee Jussim (1986) describes and analyses those situations in which one person's expectations about a second person lead the latter to act in ways that confirm the first person's expectation. 
Besides philosophers, sociologists and psychologists, economists too, have recently begun to notice the peculiarity of this trust mechanism. Some insights can be found in Dasgupta, who recognises that "the mere fact that someone has placed his trust in us makes us feel obligated, and this makes it harder to betray that trust" (1988, p.54).

One of the conclusions that we may infer from this literature is the idea that, given certain conditions, there is a natural tendency to fulfil the expectations that others have explicitly manifested by trusting us. Despite a diffuse agreement about this point, very few attempts have been made to trace the roots and explore the functioning of such a disposition. This will be the aim of the following sections.

4. Interactive motivation: the source of trust responsiveness.

Pettit advanced a potential explanation for the mechanism of Trust Responsiveness grounded on the idea that, as social individuals, we care about the good opinion of the others. By fulfilling the other's trust we confirm the other's good opinion (which is the fundamental reason for their trust in us), and that indirectly increases our own welfare, despite the fact that trustworthiness implies some material costs. Our actual behaviour will result in the epiphenomenon of that balance between material and psychological benefits and costs. Pettit's theory is built around what he calls a "shameful disposition". I think, however, that, though crucial, this motive should not be considered as the ultimate source of trustworthiness. It is also important to make clear that having a desire for the good opinion of the others should not always be considered "shameful". There is a range of motives that goes from vanity to the genuine desire of being praiseworthy, that springs from the desire for the good opinion of the others, and each of those motives has a very different moral status.

I shall focus here, in particular, on the evolution of the concept of self-love, in its broadest sense of "desire for the good opinion of the others". Such a desire is seen as the core of our social interactions, and it needs to be analysed in its different forms and dynamics.

On the one hand, we have the position developed mainly by philosophers such as Hobbes and Mandeville, according to which the mere pursuing of self-love is necessarily a source of conflict, while on the other, we have the champions of the idea of self-love as a source of love for others. There is also a third position personified mainly by Hume and 
Smith that aims at the reduction of such a dichotomy through a purification of self-love moral status. In what follows, I will focus mainly on the latter perspective.

Aristotle's theory of sociality constitutes the departing point of both Hume's and Smith's systems. Its pivotal element is the concept of philautia (literally "self-love"). Philautia is the source of philia or friendship, which is the source of self-knowledge and self-consciousness in Aristotle's system. It is by virtue of this mirroring process that in a friendly relation one has the opportunity to develop all her virtues. That is the reason why, according to Aristotle, self-love represents the bedrock of moral development and flourishing.

Hume's position $(1739,1751)$ goes explicitly against both cold cynicism (Hobbes) and candid optimism (Hutcheson), as he maintains that behaviour should be explained through a mix of coexisting selfinterest and benevolence. His crucial assumption is that of an innate sense of sympathy that generates the basic human propensity to sociality. It is through sympathy that we assess whether our actions are "useful" or "pernicious" for the others. Such an assessment is, in turn, the basis for the establishment of a sense of justice and honesty. That is why virtue is considered desirable on its own account, without fee or reward, "merely for the immediate satisfaction which it conveys". Man are generally moved by the desire for fame and reputation, a kind of desire that is not radically different from vanity. Here Hume introduces a distinction that will be further clarified by Smith between aiming at being praised and approved and aiming at being worth of praise and approval. That shift is based on what Hume defines the "reverberating" or "reflective" nature of sympathy. Such a quality implies that we aim at gaining our own approval at least as we desire to obtain the other's. Sympathy pressures us to see ourselves as we would appear to others, being pleased with our virtues and disliking our own vices. The reverberating nature of sympathy leads us to internalise other people's moral judgements, hence sympathy is responsible for the deprecation of our own vices, even though they are of great benefit.

Even more than Hume, Adam Smith considers his system of ethics as empirical and experimental and constructed to account in theoretical terms for peoples' real behaviours. He builds his Theory of Moral Sentiments around some empirical assumptions. The first assumption is similar to Hume's, namely, that the most basic motive of social action is the desire of being loved and approved: 
There is a satisfaction in the consciousness of being beloved, which, to a person of delicacy and sensibility, is of more importance to happiness than all the advantage which he can expect to derive from it (...) Nature, when she formed man for society, endowed him with an original desire to please, and an original aversion to offend his brethren. She taught him to feel pleasure in their favourable, and pain in their unfavourable regard. She rendered their approbation most flattering and most agreeable to him for its own sake; and their disapprobation most mortifying and most offensive (1759/1976, III,2.1)

In Smith's account, it is precisely such a desire that instils in each individual the ambition to improve its position and rank. "To be observed, to be attended to, to be taken notice of with sympathy, complacency, and approbation, are all the advantages which we can propose to derive from it. It is the vanity, not the ease, or the pleasure, which interests us" (I, 3. 2). But vanity and self-love alone are not enough to explain the genesis of social sentiments and their dynamics. It is necessary to introduce Smith's second assumption which is based on individuals" "separateness". We do not have a direct experience of what others feel, what we have instead is the natural ability of "feeling-with others", that is, of imagining ourselves as subject of others" experiences. People are separated but, as postulated by Hume, tend to develop a desire for sociality. Such a desire is mediated by sympathy, which in Smith's understanding refers to situations and not to feelings. That means that to sympathise with others implies not to imagine what I would feel in a given situation, but instead what the subject I am sympathising with, would feel in that situation. The extension of such an imaginative ability represents the basis for our self-consciousness, produced by our natural inclination to view ourselves as others see us. This concept, that seems to have an Aristotelian vein, (a consequence of Aristotle's philia), is explained by Smith, when he refers to the parable of that imaginary man grown up in some solitary place, without any communication with his own species; such a man will be unable to judge upon his own conduct because he lacks any reference point, any example and definition of what is proper or improper. That is so because he is provided with no mirror which can present his behaviour to his own view. It is social life that provides such a "mirror" which, according to Smith, is "placed in the countenance and behaviour of those he lives with, which always mark when they enter into, and when they disapprove of his sentiments; and it is here that he first views the propriety and impropriety of his own passions, the beauty and deformity of his own 
mind" (I, 3. 1). The ultimate consequence of the activity of reciprocal sympathy is that the subject becomes able of self-reflection. Selfawareness then results as an extension of our ability to feel with others because we evaluate ourselves as we imagine others evaluate us.

We can never survey our own sentiments and motives, we can never form any judgment concerning them; unless we remove ourselves, as it were, from our own natural station and endeavour to view them as at a certain distance from us we can do this in no other way than by endeavouring to view them with the eyes of other people, or as other people are likely to view them. (III. 1. 2)

Here we see, extended and developed, Hume's idea of the "reverberating" quality of sympathy. Smith clarifies the logic of approbation and disapprobation saying that it comes from our imaginative process which, fuelled by sympathy, leads us to imagine others' reactions and sentiments in a given situation. Through such exercise we first imagine what they would feel and then decide whether or not to conform to them. In each particular situation, conformity of sentiment suggests approbation. Are others' sentiments objective enough to guarantee an impartial judgement? If not, what could provide such a benchmark? The ability of self-approbation and self-disapprobation to avoid being mere conformistic sentiments, needs to be supplemented with a morally objective reference point. Here Smith assumes the existence of a third spectator, a "cool and impartial spectator" who, according to the logic of sympathy, does not feel the agent's emotion and sentiments to the same degree as the agent does, so that between the agent and the spectator a certain degree of detachment is provided to guarantee the desired degree of objectivity.

The impartial spectator is a logical development of the actual spectators, which our imagination provides to us. Such development produces a "judge" and a disinterested "critic" for the agent, capable of counterbalancing the latter's self-centred perspective.

At the end of this story, we have an agent who, because of her innate sociality and her sentiment of sympathy, is naturally inclined to selfevaluation. Her impartiality, of judgement, though not her absolute objectivity, is guaranteed by the action of the impartial spectator. Therefore, our actions are motivated by the desire for others' approbation that we can represent to ourselves even when the others are physically absent. But is such a desire for praise enough? Is this mechanism able to account for the whole class of behaviours that Smith 
aims to explain? What is, at this stage, the difference between the desire for praise and vanity? It is at this point that Smith, in the same line as Hume but against Rousseau ${ }^{3}$, develops his original view, based on the idea that we do not want only to be praised but also, and more fundamentally, to be praiseworthy.

Man naturally desires, not only to be loved, but to be lovely; or to be that thing which is the natural and proper object of love. He naturally dreads, not only to be hated, but to be hateful; or to be that thing which is the natural and proper object of hatred. He desires, not only praise, but praiseworthiness; or to be that thing which, though it should be praised by nobody, is, however, the natural and proper object of praise. $\mathrm{He}$ dreads, not only blame, but blame worthiness; or to be that thing which, though it should be blamed by nobody, is, however, the natural and proper object of blame (III, 2.1)

Praise and praiseworthiness do not always coincide. There are cases where we are praised for having done things that are not praiseworthy and also cases where a praiseworthy action is not followed by any praise (the same, symmetrically, applies to blame and blameworthiness). In those cases where there is a conflict between the judgement of the self and that of the others, generally, Smith claims, the former prevails.

Though a wise man feels little pleasure from praise where he knows there is no praise-worthiness, he often feels the highest in doing what he knows to be praise-worthy, though he knows equally well that no praise is ever to be bestowed upon it. To obtain the approbation of mankind, where no approbation is due, can never be an object of any importance to him (III, 2 .7).

\footnotetext{
${ }^{3}$ Rousseau is the "great absent" of this reconstruction; I prefer to confine myself to the Scottish tradition for the sake of homogeneity and brevity. Nevertheless, it has to be noted that Rousseau was the first to make explicit that the desire for approbation (amour propre) is the most powerful motif of social life. While, according to Rousseau, l'amour propre, by inflating our ego through the eyes of the others, can be considered as the origin of every virtue but also of every vice, Smith sees in this desire of recognition a powerful remedy to the ego's hypertrophy, through selfcommand. Smith's position, then, can be read as a reaction to Rousseau's original formulation.
} 
The fil rouge of the story I have briefly sketched is represented by the centrality of the desire for being loved and approved, as a primary, if not unique, source of motivation. From Aristotle's philautia, to Smith's praiseworthiness, this concept has been somehow morally purified from any residual of selfishness. According to Smith, in fact, such a desire cannot be considered neither selfish, nor self-centred, as it is based on the imaginative act of getting out of the self to get into others' contingencies. Precisely such an imaginative leap should be considered as the rationale for trustworthiness as it is depicted in the trust responsiveness mechanism.

\section{The Self-reflective nature of trustworthiness.}

Following this line of thought, I suggest that trust responsiveness is ultimately grounded on the subject's ability of self-reflection. Such an ability cannot be entirely internally generated, it arises in fact from the relationship with the other, the other that, as we have seen from Aristotle to Adam Smith, represents the mirror of our self.

In the study of trust, at least when considered in the narrow sense that I am considering here, the real puzzle, what is hard to explain with the traditional tools of rational choice theory, is not why we decide to trust someone, but instead why who has been trusted upon decides to be trustworthy. In fact, once I happen to know that you have good reasons to be trustworthy, explaining my being trustful becomes trivial. What is intriguing, then, is to find a rationale for trustworthiness when those good reasons are, by no means, manifest.

The trust responsiveness hypothesis suggests that some of the reasons for being trustworthy arise from the mere fact of being the object of someone else's trust. Smith's idea of self-reflection may constitute the starting point for providing a potential justification for that proposition. It has to be noticed that Smith's argument is only the starting point of my tentative rationalisation of trustworthy behaviour. I'm going further, in fact, with respect to his original construction, by assuming that the desire for being praised and the desire for being worthy of praise are two distinct, if related, sources of motivation. It is disputed whether in Smith's Theory those two elements could be interpreted in this way or, on the contrary, they have to be considered somehow consequential. 
Let us assume that there are two subjects, $\mathrm{A}$ and $\mathrm{B}$; let them interact in a situation similar to the Trust Game. A moves first; according to game theory she should end the game there by being prudently distrustful. Suppose instead that she decides to opt for the trustful strategy. Again, game theory tells us that B, with certainty, will be opportunistic. Suppose again that against such a prediction he decides to play trustworthily. Let's try to rationalise what kind of reasoning may motivate $\mathrm{B}$ to resist the temptation of the opportunistic move.

Firstly, let's assume that B is interested in the material payoff. Secondly, let's assume that he is interested in A's opinion as well. We know from Hume and Smith that subjects have an innate desire for the good opinion of the others and they also have the ability, through imagination, of changing their point of view with that of the others. Having observed her move, B may ask himself why A has been trustful. The reasons could be many, but if we rule out masochistic or ideally altruistic ones, all should be based on the expectation of a trustworthy response. At this stage, $\mathrm{B}$ imagines that $\mathrm{A}$ has such an expectation. What could be the rationale for such an expectation? B does not know; all he knows is that for having played trustfully, A thinks B is trustworthy. To be trusted, in fact, is to be told that one is believed to be trustworthy. Now B knows that A believes him to be trustworthy. At this stage B has two options: being trustworthy or let A down by being opportunistic. In thinking about such options, B considers two different orders of judgements: first, he tries to imagine A's reaction to both responses. Given her prior expectation, A will be satisfied with the former choice and frustrated by the latter. Because of our innate desire for the good opinion of the others, B knows that such reactions will have, respectively, a positive or a negative impact on A's opinion of him and therefore on B's "vanity". That first order of judgement affects what we may understand as B's desire for praise. There is also a second order of judgements, and precisely that coming from our own self-appraisal. Nature, in fact, has made us desire not only to be praised, but to deserve praise. This is, our concern about what an impartial and well-informed spectator would think and feel about what we are doing, and not just about the reactions of our actual spectators. In Smith's argument, the impartial spectator seems to provide a detached and objective standpoint from which the actor can look at her own conduct in a way which is "purified" from the self-centredness that ordinarily affects agents' judgement. I suggest that such a second order judgement will affect not simply B's desire for praise, but instead his desire for praiseworthiness, 
ultimately B's self-esteem ${ }^{4}$ and not his vanity, as in the previous case. At this point, then, $\mathrm{B}$ has to compare the net effect of the material gains and the psychological losses, attached to his available options: the material gain and the psychological loss from having been opportunistic, or the material loss and the psychological gain from having been trustworthy. What is important to notice here, is that the psychological impact has two sources: it does not derive only from A's idea of B, conditional to his actions, but also, and I think principally, from B's idea of his own action, as it appears from the external standpoint of the impartial spectator. This interpretation of Smith's theory of motivation seems to be supported by several pages of the Theory, where he clearly distinguishes between "those two tribunals", the action of the "man within" and that of the "man without" (II, 2. 32-33).

The mechanism of self-evaluation works in two stages. In the first, the impartial spectator determines the balance between the actor's (B) interest as agent and the spectator's (A). In the second, the impartial spectator determines B's conscience towards the action, according to what determined in the first stage. This mechanism provides what may be termed as internal psychological reasons to action. At the same time B perceives or imagines what kind of reaction A may express towards B's action. These are the external psychological reasons for B's action. Thus, $\mathrm{B}$ is in relation with two subjects, A and the "impartial spectator"; moreover, it is influenced by the reactions of both. In this sense B's action is determined by three orders of motives: first, his direct material interest; second, A's approbation or disapprobation; third, his own selfapprobation or disapprobation as derived from the perspective of the spectator. This motivational structure is neither narrowly self-interested, because it takes account of A's interests, nor narrowly self-centred, because it is partially determined by the action of the spectator that is detached and impartial. According to this mechanism, our actions are assessed and determined by the consequences that they produce on us, both internally and externally. The internal reasons are those related to our sense of worth; the external reasons are those related to our vanity. These two sources of motivation account for the difference that exists

\footnotetext{
4 Here I am using the concept of "self-esteem" as a product of a process of interactive self-valuing, that is one beginning with the relation with the other and, by extrapolation, getting to a certain conclusion regarding the relation with himself. The way in which we may value others is extended to the way which the self valus itself.
} 
between having a desire for conformity to the others' expectation because of the fear of the others' reaction, and having the same desire because of intrinsic reasons, related to one's own sense of worth. Trust responsiveness is based on both. In fact, this composite nature can explain why, for instance, we observe trustworthiness even in anonymous interactions, that is, when A's reaction cannot be directly observed. In such a situation, the action of the internal reasons may still counterbalance the subjects' material self-interest. Similarly, B does not directly perceive A's reaction, but he still may be able to imagine it. By the same means B may imagine A's reaction even before making a certain action. For the same reason, the internal reasons take place independently of the fact that A's judgement is expressed or not. It seems that such an assessment has the same necessity as a knee-jerk.

Thus, the actual choice results as the compound effect of material self-interest, others' approbation or disapprobation and a personal sense of worth. Self-worth is a second order construct. It derives from the good opinion of the self, which, in turn, she derives from the impartial spectator's approval.

I suggest that trustworthiness arises whenever material selfinterest is offset by the desire for others' approval and for selfworthiness. By being trustful you tell me that I am trustworthy; I want to fulfil such a belief because I want to be praised, certainly by you, but principally by myself.

From what I have being saying it should not be derived that "being trustworthy", in the sense of meeting someone else's expectation, is something that is generally approved. Think about this example: A and $\mathrm{B}$ are co-workers. Some job has to be done today, and it is really A's responsibility, but $A$ sneaks off before the end of the day, leaving $B$ to do the job. A's action implies that A believes that B will do the job. Is B to be considered trustworthy if he responds to A's expectations? I would not say so. In this case in fact, A's trust is presumptuous. That means that by being trustful, $\mathrm{A}$ is not signalling a good opinion of $\mathrm{B}$, quite the contrary. B's actions should be considered trustworthy, when they confirm A's expectation (signalled by a trustful move) but only when that follows from a good opinion of $A$.

The peculiar nature of trustworthiness emerges from what I said so far: it is, in fact, neither self-centred, because it is based on the other's imagined reactions, nor completely other-regarding, because it is not based exclusively on the other's opinion. I think the best way to denote the nature of trustworthiness is by using the term "relational". It comes 
about, in fact, as a product of the action of self-reflection, which in turn arises from the relation with others, others as a mirror of the self.

\section{Responsive trust is relational}

In this section I shall try to discuss and compare some of the main distinctive features of the trust responsiveness hypothesis, in particular those features that distinguish it, theoretically and observationally, from other explicative principles and theories.

Let me summarise schematically the reasoning process underlying the mechanism of trust responsiveness: suppose there are two players, A and B. A moves first and B observes A's choice; we know that:

1. $\mathrm{B}$ is interested in what $\mathrm{A}$ thinks of him;

2. if such an opinion is a good (bad) one, B experiences an increase (decrease) in utility deriving both from A's actualised good (bad) opinion [external reasons] and from his increased (decreased) sense of worth [internal reasons];

3. if A trusts (behaves trustfully towards) B, she is signalling a good opinion of B. She implicitly expects a non-opportunistic behaviour from B;

4. if $\mathrm{B}$ responds in a way that confirms (disconfirms) her expectation, B's psychological utility will increase (decrease) because of the net effect of external (A's) and internal (impartial spectator's) positive (negative) consequences of B's actions;

5. such a psychological gain (loss) has to be weighed with the material gain or loss.

6. A knows that B has a desire for A's good opinion and wants to increase his own sense of worth;

7. A anticipates that, if the material loss is not too great, such a desire will be satisfied by a trustworthy behaviour;

8. all those points are common knowledge.

Let's consider first the differences that separate trust responsiveness from traditional Rational Choice Theory. Whether it seems plausible to consider the psychological motivation arising from being the object of others' trust, as comparable and additive to the material incentives involved in the trusting relation, it is impossible to describe, a priori, the overall utility (material and psychological) before 
the interaction begins. That is precisely what the position sometimes called "tautologism" would suggest in order to reconcile "anomalous" empirical observations and standard theory (Binmore, 1998).

As I have already stressed, the mechanism of trust responsiveness is a mechanism of endogenous payoff formation. One does not know which are the players' real payoffs (only the material ones are known) before the game is actually played. What one may come to know is how the psychological part of players' utility is formed by the material one and by the conjunct effect of the players' actions and (first and second order) beliefs. This process of endogenisation of the payoffs makes trust responsiveness ontologically non-reducible to the traditional Rational Choice Theory's and Game Theory's conceptual categories. According to the Rational Choice Theory, in fact, all the "exotic forms of reasoning", like those based on reciprocity and trust, should be considered as redundant and unnecessary. One does not need to introduce reciprocity, kindness, and trust, to explain the anomalous players' behaviour in certain games; all one has to do is observe people's decisions and then write down the right payoff matrix. Trust, reciprocity, altruism and all the conceivable motives for action can be more easily included in the right game's payoffs.

I do not think that such criticism is completely ungrounded, however, if we were to push it to its extreme consequences we would incur the risk of throwing the baby with the bathwater. We should renounce, in fact, every ambition of a real understanding of the principles that ultimately rule a strategic interaction. A game could not even be described before having seen the players playing it. Such a radical position transforms the subject into a black box, depriving, in this way, the theory of any explicative ambition and confining it to the realms of mere observation and description.

There are, however, other direct and strong reasons why the idea of trust responsiveness escapes such a criticism. The "exotic" motivating elements characterising all the non-consequentialist principles, such as "trust responsiveness", based on the role of intentions, cannot be subsumed in the same numerical index that payoffs represent in Binmore's interpretation.

Whereas Binmore's objection may be referred to simpler cases, for instance altruism and inequity aversion theories, where second order beliefs are at work this is no longer valid. Second order beliefs and emotional reactions turn out to be endogenous and no single set of payoffs can adequately summarise the whole strategic situation. 
Consequently, standard game theory results in not being well suited to analyse situations contaminated by such beliefs dependent on psychological considerations as surprise, confidence, gratitude, disappointment, embarrassment, and so on. To analyse such situations properly we have to use psychological games. A psychological game is characterised by the fact that payoffs depend on each players' strategy choices, but also on what each player thinks.

The only two motivating elements considered by traditional game theory are utility and beliefs, that is, payoffs and subjective probabilities. If we assume that players seek to maximise the product of these two entities, there can be only two motivating elements, namely, the utility associated with different outcomes (exogenous) and the probability associated with other players' different strategies (endogenous). Traditional game theory also considers higher order beliefs (as logically different from first order beliefs), but such higher order beliefs are endogenous and do not have any motivating effect on players' choices. Here lies the main difference, since for trust responsiveness, second order beliefs exert a direct motivating force. In those theories, in fact, A's strategy choice is determined by A's beliefs about B's choice and by A's beliefs about B's beliefs about A's choice; whereas in traditional game theory the choice depends only on A's beliefs about B's choice. While consequences normally ranked using payoffs are exogenous, expectations depending on second order beliefs are endogenous and therefore the latter cannot be incorporated into the former.

Let me consider now the differences between trust responsiveness and the idea of reciprocity as it is conceived in Matthew Rabin's model of reciprocating fairness (Rabin, 1993). Both reciprocity and trust responsiveness are principles of norm-guided behaviour. Under certain conditions such norms may offset the effect of material payoff in the individual decision making. The effect of reciprocity and trust responsiveness may lead the subject to act in a way that appears to be contrary to her material self-interest. Both principles have an element of reciprocity since that is a hallmark of all norm-guided behaviour. They differ over the content of such norms, in particular over the mechanism that elicits the individual's psychological utility.

The idea of reciprocity is ultimately based on the joint effects of material and psychological incentives. I am not saying here simply that in players' overall utility both material and psychological incentives co-exist, that is true by definition both for reciprocity and trust responsiveness. 
What I am saying is that the motivation that triggers (positive or negative) reciprocal behaviour is based on material incentives. The perceived kindness that elicits reciprocal behaviour is a measure of material benefit that an agent's choice attributes to another player.

Precisely following this logic, Rabin formalises the idea that I feel somehow motivated to reciprocate when, from your expected action, I can get a material payoff higher than the equitable one (which constitutes a measure of fair distribution). Such an increase refers to material payoffs. Acting in a way which repays (ignores) such an expected material gain leads me to a psychological gain (loss).

The trust responsiveness hypothesis, on the contrary, is exclusively based on a psychological-moral motivation. It is the (trustful) action that produces reasons for the trustee to behave trustworthily, and not the potential beneficial consequences for her material wealth that she may derive from it. You manifest to me your expectation on my behaviour, if I consciously fulfil (frustrate) it, I get an increase (decrease) in my psychological payoff. Put another way, while reciprocity in Rabin's theory is the act of conferring benefits on people who have previously materially benefited you, trust responsiveness is the act of conferring benefits on people who have shown that they expect you to do so, and have willingly exposed themselves to harm in the event that you act on material self-interest.

Such a difference becomes clear when one considers a certain class of situations where reciprocity and trust responsiveness-based behaviours are not observationally equivalent.

Consider the logic of reciprocity applied to the particular variant of Trust Game depicted in figure 2a below. 
Figure 2a.

The Trust Game

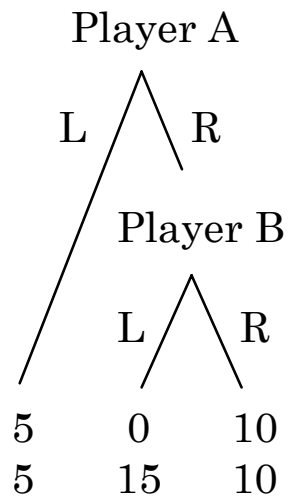

Figure 2b.

The Gratuitous Trust Game

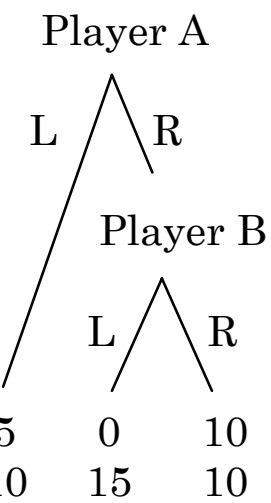

We know that reciprocity takes the form of returning kindness for kindness and unkindness for unkindness. In this game that means that if A expects B to play $\mathrm{R}$, then A playing $\mathrm{R}$ is perceived as kind by $\mathrm{B}$ who in turn feels motivated to play R. Consider now the instance of the Trust Game depicted in figure 2b. What result would the logic of reciprocity produce in this particular game? Now, in fact, if A expects B to play $\mathrm{R}$, A playing $\mathrm{R}$ does not provide any benefit to $\mathrm{B}$, if $\mathrm{B}$ expects $\mathrm{A}$ to play $\mathrm{R}$, therefore the logic of reciprocity would suggest $\mathrm{B}$ to play $\mathrm{L}$, straight away.

What about trust responsiveness? If, on the contrary, we consider a trust responsive $\mathrm{B}$ player, we would observe him playing $\mathrm{R}$ in both situations, despite the difference in the material benefits he would obtain from A's move.

I have labelled the latter particular form of trust game as the "Gratuitous Trust Game", expressly to emphasise that in this game any instance of co-operative behaviour cannot be thought as an exchange of material benefits. 
These examples shed light on the difference between trust responsiveness and reciprocity on the issue of material/non material incentives to action.

However, there is a more basic distinction between reciprocity and trust responsiveness that refers to the different degrees of relationality or interpersonal responsiveness. In Rabin's theory, in fact, such an interpersonal responsiveness takes the form of being kind to someone who has been kind to us and to punish who has been mean. We have emphasised the limits of this logic with the example of the Gratuitous Trust Game. In that situation, since A would receive some benefit from her playing $\mathrm{R}$, provided that $\mathrm{B}$ would in turn play $\mathrm{R}$, such a move cannot be perceived as kind, and therefore cannot call for positively reciprocal behaviour from B. But although A has not been kind to $\mathrm{B}$, she has nevertheless trusted him. That emphasises the fact that reciprocal kindness seems to appear as a subclass of trust responsive behaviour.

\section{Conclusions.}

According to John Locke, trust and trustworthiness represent the vinculum societatis, the bond of society. They are crucial to the sustaining of a well ordered community and even to the efficient functioning of the market. In this paper we have explored the idea of trust responsiveness, a mechanism according to which trustworthiness may be elicited by trust. Trustworthiness appears grounded on the subjects' ability of self-valuing. This paper provides a philosophically oriented discussion of the sources of such an idea. In particular, I have tried to trace back its roots in the anthropological models developed first by Aristotle but especially by Hume and Smith, who suggest that our most basic reasons for action are grounded both on our desire for others' approval and, more intensely, on our desire for our own. The "degree of relationality" is discussed and used to distinguish between trust responsiveness and other observationally equivalent explanations of trust. 


\section{References}

[1] - Bacharach, M. Guerra, G. Zizzo, D. 2004. The SelfFulfilling Property of Trust: An Experimental Study, mimeo, University of East Anglia, Norwich.

[2] - Baron, J. 1998. Trust: Beliefs and Morality, in BenNer and Putternam (1998).

[3] - Ben-Ner, A. Putternam, L. (eds.) 1998. Economics, Values and Organisation, Cambridge, Cambridge University Press.

[4] - Binmore, K. 1998. Theory of Game and Social Contract. Just Playing Vol 2. Boston MA., MIT Press.

[5] - Bruni, L. Porta, P.L. 2005. Handbook of Happiness in Economics. Cheltenham, Edward Elgar.

[6] - Bruni, L. Sugden, R. 2000. Moral Canals: Trust and Social Capital in the work of Hume, Smith and Genovesi, Economics and Pbilosophy, Vol. 16, pp. 21-45.

[7] - Dasgupta, P. 1988. Trust as a Commodity, in Gambetta Diego (1988).

[8] - Dufwemberg, M. Gneezy, U. 2000. Measuring Beliefs in an Experimental Lost Wallet Game, Games and Economic Behavior Vol. 30, pp. 163-182.

[9] - Fehr, E. Schmidt, K. 1999. A Theory of Fairness, Competition and Cooperation, Quarterly Journal of Economics, 114, pp. 817-868.

[10] - Gambetta, D. (ed.) 1988. Trust: Making and Breaking Cooperative Relations. Oxford, Basil Blackwell.

[11] - Hollis, M. 1998. Trust whithin Reason, Cambridge, Cambridge University Press.

[12] - Horsburgh, H. 1960. The Ethics of Trust, Pbilosophical Quarterly. Vol. 10, pp.343-354.

[13] - Hume, D. 1739/1978. Treatise on Human Nature, Oxford, Clarendon Press.

[14] - Hume, D. 1751/2001, An Enquiry Concerning the Principles of Morals. "Project Gutenberg" On-line Edition.

[15] - Jussim, L. 1986. Self-fulfilling prophecies: A theoretical and integrative review, Psychological Review, Vol. 93, pp. 429-445.

[16] - Locke, J. 1660/1954. Essays on the Law of Nature, Oxford, Clarendon Press. 
[17] - Margolis, H. 1982. Selfishness, Altruism, and Rationality. A Theory of Social Choice, Chicago, Chicago University Press.

[18] - Pelligra, V. 2002. Trust \& Economics: Theoretical and Experimental Investigations, Ph.D. Thesis. University of East Anglia

[19] - Pelligra, V. 2005. The not-so-Fragile Fragility of Goodness, in Bruni, L. Porta, P.L. (2005)

[20] - Pettit, P. 1995. The Cunning of Trust, Philosopby and Public Affairs, Vol. 24, pp.202-25

[21] - Rabin, M. 1993. Incorporating Fairness in Game Theory, American Economic Review, Vol. 83, pp. 1281-301

[22] - Smith, A. 1759/1976. The Theory of Moral Sentiments, Indianapolis, Liberty Classics.

[23] - Sugden, R. 1993. Thinking as a Team: Towards an explanation on non-selfish behaviour, Social Pbilosophy and Policy, Vol. 10, pp. 69-89. 


\section{Ultimi Contributi di Ricerca CRENoS}

I Paper sono disponibili in: http://www.crenos.it

06/14 Rinaldo Brau, Alessandro Lanza, Francesco Pigliaru "How fast are small tourist countries growing? The 19802003 evidence"

06/13 Emanuela Marrocu, Raffaele Paci "The effects of public capital on the productivity of the Italian regions"

06/12 Raffaele Paci, Stefano Usai "Agglomeration economies and growth-the case of italian local labour systems, 1991-2001"

06/11 Fabrizio Ariani, Luca G. Deidda "The Monopolist's Blues"

06/10 Bianca Biagi, Dionysia Lambiri, Vicente Royuela "Quality of life in the economic and urban economic literature"

06/09 Manuela Pulina, Bianca Biagi "Tourism, environmental quality and economic growth: empirical evidence and policy implications"

06/08 Gianfranco E. Atreni, Oliviero A. Carboni, "Regional disparity in ict adoption: an empirical evaluation of the effects of subsidies in Italy"

06/07 Isabel Cortés-Jiménez, "Tourism and economic growth at regional level: the cases of Spain and Italy"

06/06 Maria Gabriela Ladu, "Total Factor Productivity Estimates: some evidence from European Regions"

06/05 Gerardo Marletto, "La politica dei trasporti come politica per l'innovazione: spunti da un approccio evolutivo"

06/04 Elisabetta Strazzera, "Application of the ML Hausman approach to the demand of water for residential use: heterogeneity vs twoerror specification"

06/03 Silvia Loddo, "Structural Funds and Regional Convergence in Italy"

06/02 Fabio Cerina, "Tourism specialization and environmental sustainability in a dynamic economy"

06/01 Emanuela Marrocu, Raffaele Paci e Francesco Pigliaru, "Gli effetti del capitale pubblico sulla produttività delle regioni italiane"

05/14 Rinaldo Brau and Davide Cao, "Uncovering the macrostructure of tourists' preferences. A choice experiment analysis of tourism demand to Sardinia"

05/13 Barbara Dettori, Raffaele Paci and Stefano Usai, "Technological activity in European regions" 
05/12 Rosina Moreno, Raffaele Paci and Stefano Usai, "Innovation clusters in European regions"

05/11 Luca Deidda and Bassam Fattoub, "Bank, financial markets and growth"

05/10 Fabio Cerina and Francesco Pigliaru, "Agglomeration and growth in NEG: a critical assessment"

05/09 Maurice Kugler and Rossella Oppes, "Collateral and risk-sharing in group lending: evidence from an urban microcredit program"

05/08 Adriana Di Liberto, "Convergence and divergence in neoclassical growth models with human capital"

05/07 Maria Gabriela Ladu, "Growth and employment: a survey on the demand side of the labour market"

05/06 Maria Gabriela Ladu, "Total factor productivity growth and employment: a simultaneous equations model estimate"

05/05 Silvia Balia, "Health and economic behaviour: a critical survey of the literature"

05/04 Gianna Boero, Tiziana Laureti and Robin Naylor, "An econometric analysis of student withdrawal and progression in post-reform Italian universities"

05/03 Vittorio Pellagra, "Banking with sentiments. A model of fiduciari interactions in micro-credit programs"

05/02 Margarita Genius and Elisabetta Strazzera, "Modelinf elicitation effects in contingent valuation studies: a Monte Carlo analysis of the bivariate approach"

05/01 Fabio Cerina, "Marshall's ceteris paribus in a dynamic frame"

04/20 Rinaldo Brau and Carlo Carraio, "The economic analysis of voluntary approaches to environmental protection. A survey"

04/19 Cristina Murroni, "ICT and local development: a case study of the metropolitan area of Cagliari"

04/18 Adriana Di Liberto, "Convergence clubs and the role of human capital in Spanish regional growth"

04/17 Stefano Usai and Marco Vannini, "Banking structure and regional economic growth: lessons from Italy"

04/16 Silvia Balia and Andrew M. Jones, "Mortality, lifestyle and socioeconomic status"

04/15 Rosina Moreno, Raffaele Paci and Stefano Usai, "Geographical and sectoral clusters of innovation in Europe"

04/14 Gianfranco Atzeni and Oliviero Carboni, "ICT productivity and firm propensity to innovative investment: learining effects evidence from Italian micro data"

04/13 Fabrizio Ariani and Luca G. Deidda, "Few bad apples or plenty of lemons: which makes it harder to market plums?" 
04/12 Giovanni B. Concu, "A choice modelling approach to investigate biases in individual and aggregated benefit estimates due to omission of distance"

04/11 Giovanni B. Concu, "Effects of distance aon non-use values"

04/10 Antonio Sassu and Sergio Lodde, "Le tecnologie dell'informazione e della comunicazione nelle piccole imprese dei settori maturi"

04/09 Riccardo Marselli e Marco Vannini, "L'efficienza tecnica dei distretti di Corte d'Appello italiani: aspetti metodologici, benchmarking e arretrato smaltibile"

04/08 Rinaldo Brau, Matteo Lippi Bruni and Anna Maria Pinna, "Public vz private demand for covering long term care expenditures"

04/07 Matteo Bellinzas, "Dinamiche demografiche, agglomerazione e determinanti economiche. Il caso italiano"

04/06 Giuseppe Medda, Clandio Piga, "R\&S e spillover industriali: un'analisi sulle imprese italiane"

04/05 Adriana Di Liberto, Roberto Mura, Francesco Pigliaru, "How to measure the unobservable: a panel technique for the analysis of TFP convergence"

04/04 Vittorio Pelligra, "How to incentive Who? Intr-personal and interpersonal mechanisms"

04/03 Domenica Giovanna Dettori, Antonello Paba, Manuela Pulina, "European rural Tourism: agrotouristic firms in Sardina and their life cycle"

04/02 Giovanni Sulis, "Wage dispersion and Equilibrium search models: some evidence from Italy"

04/01 Silvia Loddo, "Old and new intervention policy: A survey of empirical studies for the Mezzogiorno"

03/13 Raffaele Paci, Emesto Batteta, "Innovation Networks and Knowledge Flows across the European Regions"

03/12 Antonio Sassu, Sergio Lodde, "Piccole imprese e tecnologie della comunicazione: un'indagine empirica"

03/11 Antonio Sassu, Sergio Lodde, "Tradizione e innovazione nel settore vinicolo in Sardegna"

03/10 Rosina Moreno-Serrano, Raffaele Paci, Stefano Usai, "Spatial distribution of innovation activity. The case of European Regions"

03/09 Rinaldo Brau, Alessandro Lanza, Francesco Pigliaru, "How fast are the tourism countries growing? The cross-countries evidence"

03/08 Margarita Genius, Elisabetta Strazzera, "The copula approach to sample selection modelling: an application to the recreational value of forests"

03/07 Guido Ascari, Emanuela Marrocu, "Forecasting inflation: a comparison of linear Phillips curve models and nonlinear time series models" 
03/06 Alessandro Lanza, Matteo Manera, Massimo Giovannini, "Oil and product price dynamics in international petroleum markets"

03/05 Rinaldo Brau, Gianluca Fiorentini, Matteo Lippi Bruni, Anna Maria Pinna, "La disponibilità a pagare per la copertura del rischio di non autosufficienza: analisi econometrica e valutazioni di policy"

03/04 Gianfeanco Atzeni, Claudio Piga, "Credit Rationing in High-Tech Firms and Sample Selection"

03/03 Manuela Pulina, "Quantitative forecasting for tourism: OLS and ARIMAX approaches"

03/02 Gianna Boero, Riccardo Pinna, "Durata degli studi e voto di laurea: un'indagine econometrica su alcune facoltà dell'Università di Cagliari”

03/01 Anna Maria Pinna, Miriam Manchin, "Border Effects in the Enlarged EU Area. Evidence from Imports to Applicant Countries"

02/12 Gianna Boero, Riccardo Pinna, "La performance esterna dell'Università di Cagliari: il caso delle facoltà del polo giuridico-economico"

02/11 Sergio Lodde, "Patti territoriali e specializzazione produttiva nel Mezzogiorno"

02/10 Maria Grazia Curreli, Sergio Lodde, "Saperi tradizionali e sviluppo locale: il comparto della produzione del miele in Sardegna"

02/09 Gianna Boero, Jeremy Smith, Kenneth F. Wallis, "The properties of some goodness-of-fits tests"

02/08 Gianna Boero, Emanuela Marrocu, "The performance of SETAR models: a regime conditional evaluation of point, interval and density forecasts"

02/07 Anna Maria Pinna, Carla Fancello, "How far do we trade intermediate inputs?"

02/06 Sonia Deidda, Raffaele Paci, Stefano Usai, "Spatial Externalities and Local Economic Growth"

02/05 Elisabetta Strazzera, Rinaldo Brau, Silvia Balia, Simone Atreni, "La disponibilità a pagare e le preferenze dei turisti per i siti del Parco Geominerario della Sardegna: il caso di Porto Flavia"

02/04 Rinaldo Brau, Massimo Florio, "Privatisations as price reforms: Evaluating consumers' welfare changes in the UK"

02/03 Luca Deidda, Fabio Cerina, "Do we need more time for leisure?"

02/02 Luca Deidda, Bassam Fattouh, "Concentration in the Banking Industry and Economic Growth"

02/01 Raffaele Paci, Silvia Saddi, "Capitale pubblico e produttività nelle regioni italiane" 
Finito di stampare nel mese di Dicembre 2006

$$
\text { Presso Editoria\&Stampa }
$$

Zona Industriale Predda Niedda str. n. 10 07100 Sassari 
www.crenos.it 